\title{
A Study of Maintaining and Improving the WASH Services Provided by Local and International Agencies in Selected Refugee Camps in Kurdistan Region, IRAQ
}

\author{
Sarko Sabir Ahmed ${ }^{1}$
}

\begin{abstract}
Hosting a massive number of refugee in Kurdistan Region of Iraq which is above 2 million people in both category of internal displaced people and refugees, while the technical and economical capacities of the local government are limited which results the provision of water, sanitation and hygiene challenging for both local people and the surrounding environment. The aim of this research is benchmarking the current WASH services in the existing refugee camps, identifying the major difficulties within WASH service provision and highlighting the impact of current WASH practices on physical environment. The intervention of this research includes the camps in both Erbil and Sulaimanyah provinces of Iraqi-Kurdistan. The international and local agencies have been evaluated regarding WASH services provision in selected refugee camps. Detailed interviews were conducted with 6 service provision agencies' representatives to record their approaches while, questionnaire was administered among 395 refugees in addition with personal observation to determine at what extend the services are adequate and sustainable. It has been observed that both local and international organizations claimed to have sufficient WASH services but on ground, there are big challenges facing the process of WASH service provision. In general, it has been found that, most of the service providers are not concern with environmental risks which may cause by lack of sufficient WASH services. . There are several environmental issues in the camps, including lowering groundwater table, and increasing soil pollution as a result of unmanaged wastewater disposal and Excreta management. Public health problems in the camps are due to dispose black water into the pits while the groundwater is the main water supply source in the refugee camp.
\end{abstract}

Keywords: Water, Sanitation, Hygiene, Environment, Waste Management, Groundwater

\section{Introduction}

On the global scale, water sanitation and hygiene which is denote by WASH becomes a vital basic life service. Potable drinking water, and improved sanitation practices is important for sustaining human life, and keeping humans healthy. The United Nations defines the accessibility to clean water and improved sanitation practices as basic human rights (UN, 2015). WASH is a comprehensive sector which consists of three main functions which are, water supply, sanitation and hygiene. Water supply includes several processes such as, using a clean water source for supplying, distribution and storage systems, latrine construction, waste disposal and drainage. In addition hygienic promotion to keep human body clean, in order to prevent spreading water borne diseases. Referring to the most updated estimation, more than 663 million people 
around the globe do not have access to potable water for drinking, and 2.4 billion people do not have suitable sanitation facilities (UNICEF, WHO, 2015). There is no mechanism for estimating the portion of global population who have good hygiene practices but there are several studies on hand washing and other hygienic practices conducted in 19 different countries. It was observed that $19 \%$ of people wash their hands after defecation (WSSCC, 2005).

In emergency situations after natural disasters or in war zones, people leave their homes and displacing to a safer area. In their temporary homes which is usually a camp with several tents for each family, people rely on unsafe or untreated water for their domestic use from an unmanaged distribution system. In addition to that, problems with poor sanitation practices are directly linked to water as people may practice open defecation close to the water sources. Due to the unavailability of improved sanitation and not having cleaning kit for keep their bodies clean after defecation, is another major problem. Providing immediate WASH services to the camps and areas where the displaced or refugee people are living is really important for improving public health in those areas and their surroundings.

Inadequate clean water along with unimproved sanitation facilities have ramifications on human health and it causes different water-borne diseases. There are different types of water related diseases such as, schistosomiasis, malaria and diarrhea. It is estimated that every year 842,000 deaths are caused by water-borne diseases in developing countries worldwide (WHO, 2006). Assessment on importance of sanitation and clean water shows that, lack of adequate sanitation facilities results in five thousands deaths everyday (Bartram, 2010). In refugee situation, there are two major risks on public health in case of not having sufficient WASH services. One of the risks is using unsafe water for drinking, and the other risk is spreading diseases in the human waste settlement areas (Kandoh, 2012). In most of the Refugee Camps in KRI, the black water disposes in to septic tanks beneath the latrines. A research on the impacts of recharging groundwater by disposing wastewater into the ground shows that, wastewater contains high concentrations of microbiological, and chemical contaminants it could harm the groundwater quality and causes aquifer contamination (Aertgeerts, 2003).

Millennium Development Goals Declaration in 2000 aimed to reduce the portion of people without access to safe drinking water as well as the proportion of people who do not have access to basic sanitation by half. This can be gained by having an integrated water resources management, to supply sufficient amount of water to people as well as avoiding water wastage.

Because of the political and security instability in the area, the KRI hosts over two million refugees and internal displaced people in which they distributed among the three provinces (Rudaw, 2015). There are twelve refugee and IDP camps in the region which have different population. (UNHCR, 2014). The provision of services including WASH services is managed by different local and international humanitarian agencies and NGOs. Currently 14 different agencies are working as WASH service providers inside the refugee camps. The WASH sector is one of the most important parts of refugee camp management. This sector consists of three main parts which are, supplying sufficient clean water, sanitation, and hygiene promotion including construction, operation and management. 


\section{Research methodology}

\subsection{Study area}

The study focuses on the Refugee Camps in the two biggest provinces of Kurdistan Region of Iraq, which are Erbil and Sulaimanyah. The camps were selected based on the most critical situation with regard to water, sanitation, and hygiene services. The camps selected have been assessed in this study are Qushtapa, Darshakran, and Kawergosik camps. In addition with selected camp in Sulaimanyah is Arbat camp. Figure 2.1 indicates the location of the major refugee camps in KRI, the selected camps are highlighted as a cycle

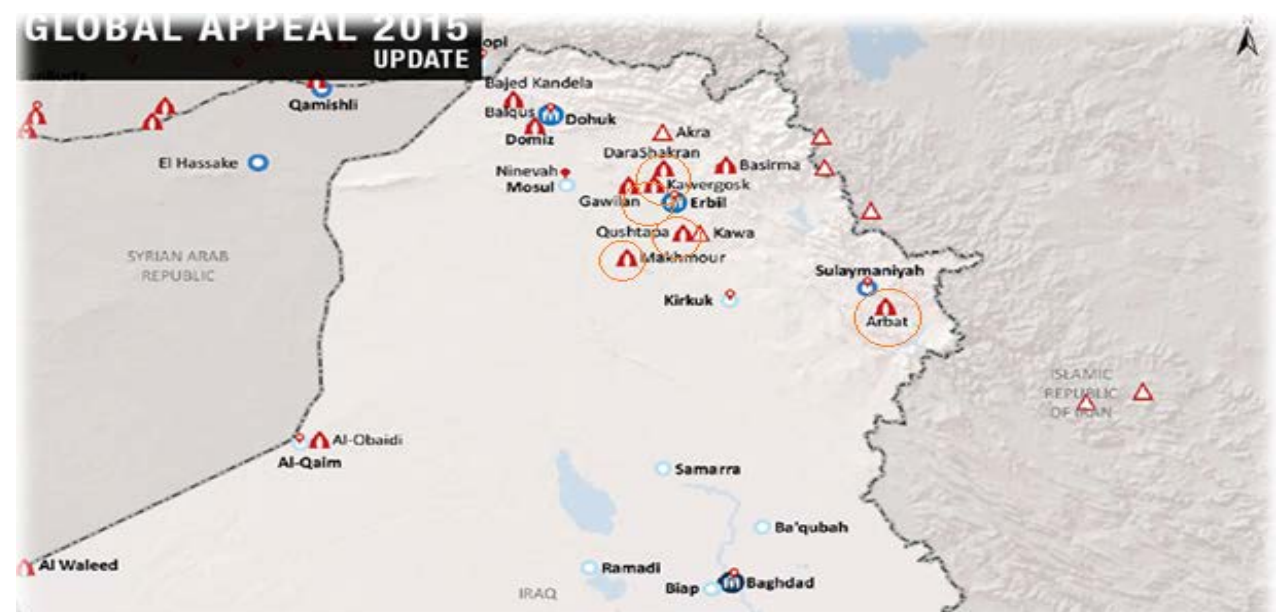

Figure2.1: Map of Northern Iraq, showing the selected refugee camps (Global appeal, 2015)

\subsection{Data collection}

Both primary and secondary data were used for this study. Primary data collected by conducting to questionnaires among refugees in the selected camps and also by using interview method with people who are in charge in the service provider agencies. For determining the sample size for the questionnaires Solvin's formula was used.

Table 2.2: shows the population and sample size in each camp

\begin{tabular}{|l|l|l|l|}
\hline \multirow{2}{*}{ Refugee Camp } & \multicolumn{2}{|l|}{ Population } & \multirow{2}{*}{ Sample Size } \\
\cline { 2 - 3 } & Individuals & Households & \\
\hline Arbat Camp & 7,208 & 1,942 & 98 \\
\hline Qushtapa Camp & 6,503 & 2,679 & 98 \\
\hline Darashakran Camp & 10,963 & 2,350 & 100 \\
\hline Kawergosik Camp & 10,336 & 2,710 & 100 \\
\hline
\end{tabular}

Solvin's formula were used to get the size of sample for each camp. 
Replace the formula in proper position of page

$$
\begin{aligned}
& n=\frac{N}{1+N e^{2}} \\
& \text { where } \mathrm{n}=\text { sample size } \\
& N=\text { population size } \\
& e=\text { margin of error }
\end{aligned}
$$

Solvin's formula

\section{Results and discussion}

The evaluation of provided WASH services for refugees has been carried out by comparing the provided WASH services and determining that to what extend the services are meeting the international standards. Refugee satisfaction regarding WASH services provision has also been considered. [Both UNHCR and The Sphere Project guidelines defined the minimum WASH services that should be given to refugees to sustain their well-being.] In general observation in the selected refugee camps, the provided water for drinking and the constructed latrine with drainage are not meeting the international standards requirements. Figure 3.1 shows that, approximately half of the agencies which work as WASH service providers stated that, their services are not up to the mark. Lack of budget is the justification provided by development organizations for inadequate WASH service in Camps.

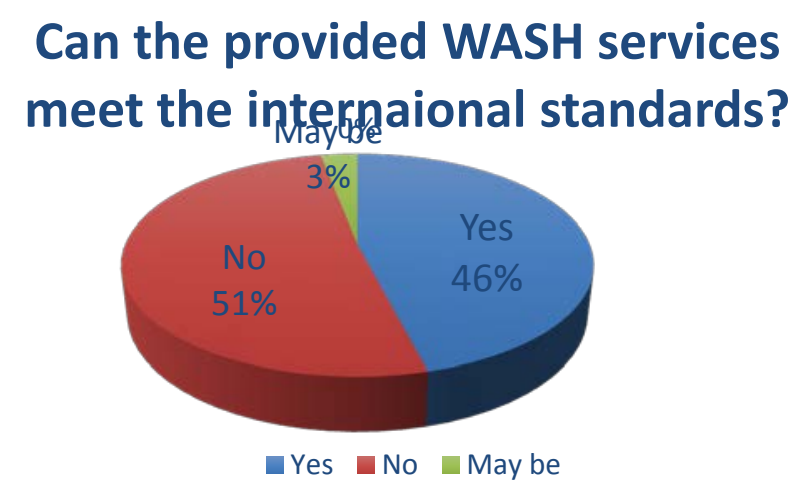

Figure $3.1 \mathrm{WASH}$ service and International Standards

As WASH service includes water for domestic purpose, sanitation with waste management, and hygiene. Supplying water to refugees, the WASH practitioners re 
usually depending on groundwater for supplying domestic purposes in the refugee camps due to immediate access. However, sometimes especially in the dry seasons they provide water by using water-truck to take the water from near surface sources.

83 percent of the WASH serve providers in the selected camps are depending on the groundwater source by using at least three boreholes in each camp, while none of these service providers were aware about the capacity of the aquifer/water table.

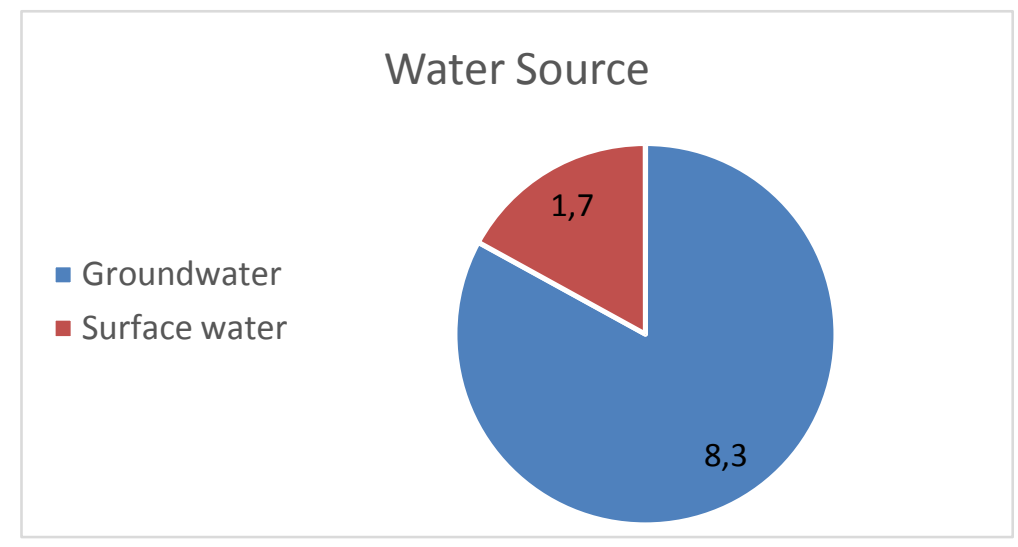

Figure 3.2 the type of water source

The WASH service providers were depending on the surface sources close to the camps. Due to lack of storage facilities in the camps users are forced to store the water in unhygienic way.

The figure 3.2 shows that only $1.7 \%$ people are dependent on surface water. Often water scarcity fix by service providers is by mean of fetching water from surrounding area with the help of water-truck. The water treatment system found in the selected camps were not appropriate. There were no advanced treatment system available. Not only that, but also the water is not available especially during the dry season, the figure 3.3 shows the duration of water availability in the selected camps each day. 


\section{The availability of water in the camps}

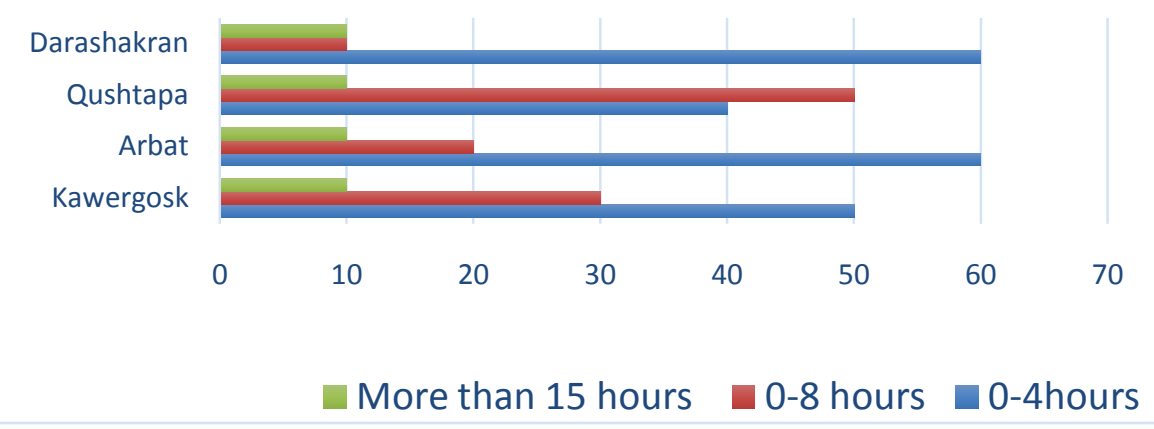

Figure 3.3: shows the hours of water availability in the camps

One of the major risks in the camps with respect to environment is unsafe disposal of wastewater. current practice to handle wastewater is conventional as they dispose black water into underground by using septic tank in addition with disposal of grey water into unmanaged open drainages close to the tends. Figure 3.4 shows the percentage of the wastewater discharge methods used in the selected camps.

\section{WASTEWATER MANAGEMENT}

subsurface drianage $\quad$ open drainage unmanaged drianage

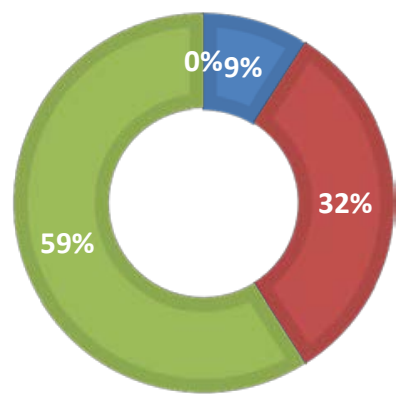

Figure 3.4 shows the percentage of drainage types in the camps

There are two possibilities as consequences of not having improved wastewater system, first one is the impacts on public health, and second is on environment as pollution. It has been observed that in majority of the selected camps septic tank is being used as black water discharge system Which un safe and might be the cause of Biological contaminants in water using by people in the Camps. Furthermore, public health in both refugee community and hosting community are also vulnerable as well. As it is showing 
in figure 3.3, the short distance between boreholes and storage tanks also providing opportunity for contamination.

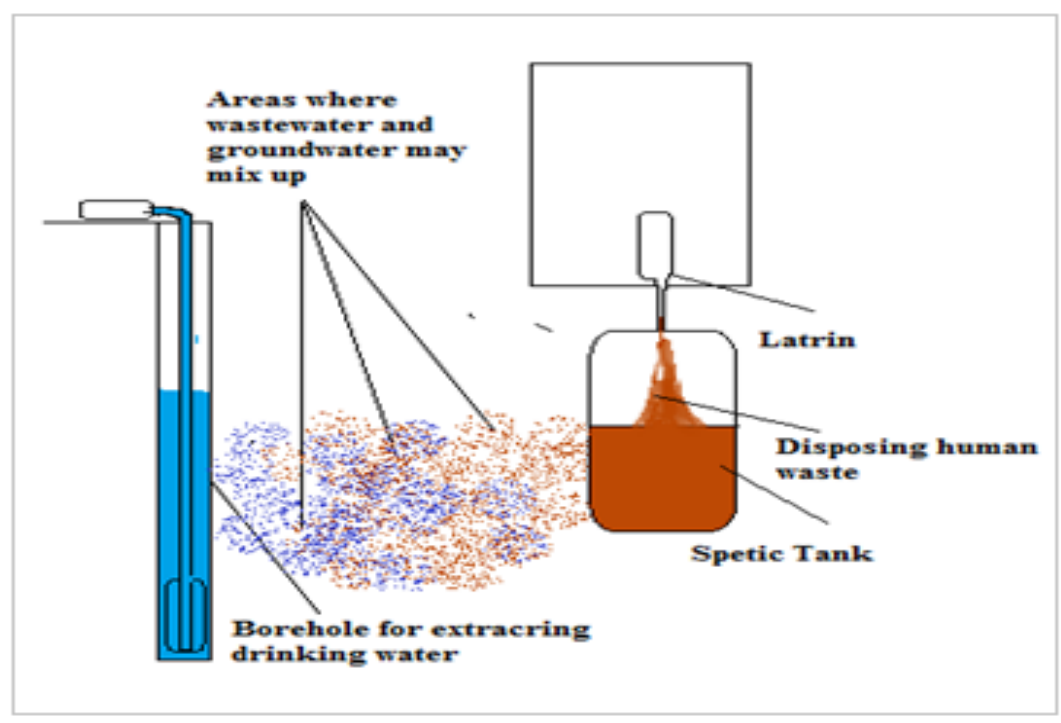

Figure 3.5 the possibility of mixing black water and groundwater

Hygiene was also observed as an important indicator of WASH service. Number of problems have been observed regarding WASH services provided by service providers as a local and international practitioners The WASH service providers in the selected refugee camps were not providing hygiene kit on weekly to better facilitate. Financial limitations and the high number of refugees is the justifications which the service providers were claiming for not providing hygiene kit. Figure 3.6 shows the results of the respondent of the questionnaire about hygiene kit provision. It $t$ would be a better option if they camp management could provide hygiene kit like soaps in the black market inside the camps with reasonable prices, so if they service providers could not provide enough kit the user could afford it by themselves. 


\section{Hygiene kit Provison}

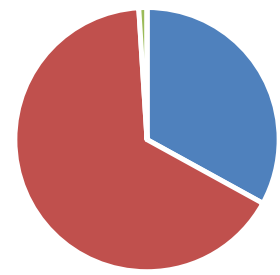

- Service Providers - Ourself $\quad$ We Don't have it

\section{Figure 3.6 Hygiene kit providers for refugees}

The result which gained by using second questionnaires among refugees with disabilities showed that, the services in the selected camps were not adequate for disable population. Figure 3.4 shows the expressions of the disabled WASH user toward the services.

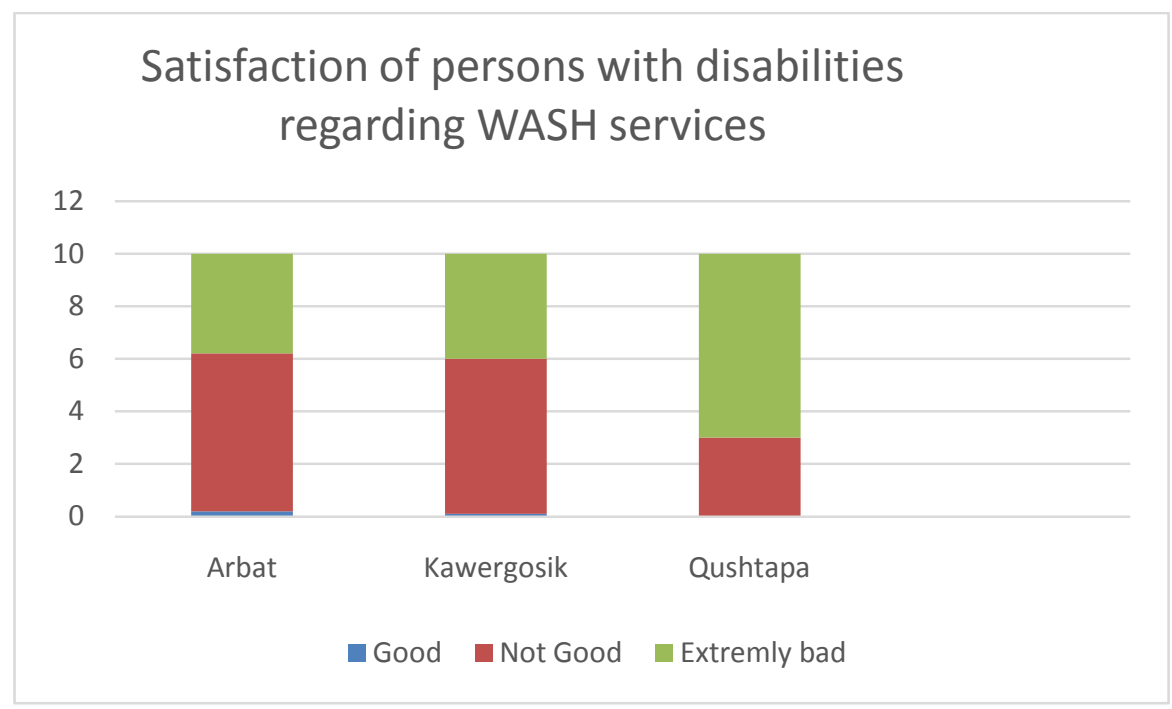

Figure 3.7 WASH and People with disabilities

\section{Conclusion:}

Providing sufficient WASH service for refugees is an important step toward protecting public health in both refugee community and hosting community, along with protecting environment; avoiding groundwater contamination, aquifer pollution, and soil pollution. Environmental sustainability as well as socio-economy sustainability could not be protect without having the minimum water, sanitation, and hygiene services for the 
displaced people. Refugee or local people should be part of every developmental project as a participation at different phases of the project. There should be a pre-assessment study to measure exact need of the refugee population the camp construction, to build up the facilities inside the camp in an adequate way. The use of groundwater should be well managed to avoid drying out the aquifer, and the water goes under improved treatment before supplying. Grey water needs to be disposed in a sufficient subsurface drainage system otherwise the soil would be polluted and public health would be under serious risks. Disposing black water to the septic tanks could have impacts on shallow ground water quality and the water which would be extracted by means of borehole would be also affected. If the service providers do not provide hygiene kit to the refugees, it is more likely that the refugees could not afford to buy hygiene kit especially soaps, could increase the risk of water related diseases outbreak. . Finally, the WASH services in the selected refugee camps inside KRI are not adequate and they need immediate improvement to ensure that the refugees have sufficient drinking water, proper sanitation, availability of toilets and awareness and provision of hygiene related matters and accessible WASH service, to provide appropriate WASH services in a way to protect local environment and Health of Refugee and local community

\section{References}

1- Aertgeerts, R. (2003). Health risks in aquifer recharge using reclaimed water. Copehangn: WHO.

2- Rudaw. (2015, October 25). Official: IDPs make up 35 percent of Kurdistan region population. Retrieved January 25, 2016, from http://rudaw.net/english/kurdistan/201020153

3- Kandoh, M. M. (2012). Forced Migration: Socio-economic Implications for Hosts Communities. Oslo : Oslo University College.

4- WHO. (2006). Meeting the MDG drinking water and sanitation target : the urban and rural. Geneva : World Health Organization .

5- UN. (2015). Highlighting the right to sanitation. New York : United Nations .

6- UNHCR. (2014). Syrian Refugee response in Iraq. Baghdad: UNHCR.

7- UNICEF, WHO. (2015). Progress on Sanitation and Drinking Water . NEW YROK: UNICEF.

8- WSSCC. (2005). Sanitation and Hygiene Promotion. Geneva : Water Supply and Sanitation Collbrative Council . 